DOI: http://dx.doi.org/10.11606/issn.1984-4867.v26i3p616-638

\title{
Capital Social e Redes Sociais Empreendedoras na Criação e Crescimento de uma Empresa de Cicloturismo
}

\section{Social Capital and Entrepreneurial Social Netoworks in the Creation and Growth of a Cycle Tourism Firm}

\section{Capital Social y Redes Sociales Empresariales em la Creacion y Crecimiento de una Empresa de Cicloturismo}

Fernando Antonio Prado Gimenez ${ }^{1}$

Sara Culti Gimenez ${ }^{2}$

\begin{abstract}
Resumo
A literatura de empreendedorismo tem apontado o capital social como um fator de sucesso na criação de novas empresas. Capital social ajuda os empreendedores em identificar e adquirir diferentes tipos de recursos por meio das redes sociais. O objetivo deste trabalho é analisar o papel das redes sociais e do capital social na criação e crescimento da Kuritbike Cicloturismo Urbano, uma empresa que atua no negócio do ciclo turismo em Curitiba - PR há quatro anos. O capital social pode ser conceituado como a rede de relações do empreendedor e os recursos que podem ser mobilizados por meio dessa rede na construção e crescimento da empresa. $\mathrm{O}$ estudo adotou uma abordagem qualitativa, por meio de uma estratégia de estudo de caso único. A empresa objeto do estudo foi selecionada em função de ser a única atuando em seu setor na cidade de Curitiba, o que evidencia um comportamento inovador por parte de seu fundador. Os resultados confirmaram que redes sociais são uma importante fonte de capital social para o empreendedor, nos estágio de criação e crescimento da empresa.
\end{abstract}

Palavras-chave: Cicloturismo; Capital social; Empreendedorismo

\begin{abstract}
The entrepreneurship literature has pointed out that social capital is a success factor in the creation of new firms. Social capital helps entrepreneurs in identifying and acquiring different kinds of resources through social networks. The aim of this paper is to analyze the role of social networks and social capital in the creation and growth of KuritBike Cicloturismo Urbano, a firm that has been operating in the cycle tourism trade at Curitiba Pr for four years. Social capital is conceptualized as a relations network hold by the entrepreneur and the resources that can be mobilized through this network in the creation and growth of a firm. The paper adopted a qualitative approach using a single case study strategy. The firm that was studied was chosen due to the fact that it is the only enterprise

\footnotetext{
${ }^{1}$ Professor Titular do Departamento de Administração Geral e Aplicada da Universidade Federal do Paraná. Doutor em Administração. Brasil. E-mail: fapgimenez@gmail.com

${ }^{2}$ Bacharel em Turismo e Especialista em Gestão de Serviços de Saúde. E-mail: sara.gimenez@hotmail.com
} 
operating in this sector at Curitiba, thus, revealing its entrepreneur's innovative behavior. Results confirmed that social networks are an important source of social capital for the entrepreneur, both in the creation and growth stages of the business.

Keywords: Cycle tourism; Social capital; Entrepreneurship

\section{Resumen}

La literatura sobre el espíritu empresarial ha señalado el capital social como factor de éxito en la creación de nuevas empresas. El capital social ayuda a los empresarios a identificar y adquirir diferentes tipos de recursos a través de las redes sociales. El objetivo de este estudio es analizar el papel de lãs redes sociales y el capital social en La creación y crecimiento de Kuritbike Cicloturismo Urbano, una empresa dedicada al cicloturismo en Curitiba, Pr desde hace cuatro años. El capital social puede ser definido como la red de relaciones del empresario y de los recursos que pueden movilizarse a través de esa red en la construcción y el crecimiento de la empresa. El estudio utilizó una aproximación cualitativa a través de una estrategia de estudio de caso único. La empresa del estudio fue seleccionada sobre la base de ser el única en su sector en la ciudad de Curitiba, que pone de manifiesto un comportamiento innovador de su fundador. Los resultados confirmaron que las redes sociales son una fuente importante de capital para el empresario durante las etapas de la creación y crecimiento de la empresa.

Palabras clave: Cicloturismo; Capital social;Espíritu Empresarial

\section{Introdução}

A criação de uma nova empresa envolve uma série de decisões, algumas simples, outras complexas, mas todas voltadas para a sustentabilidade em longo prazo do empreendimento que surge. Esse conjunto de decisões passa inicialmente por escolher o campo de atuação da empresa, decidindo sobre que produtos ou serviços oferecer em que mercados. Adicionalmente, é preciso escolher ou buscar tecnologias que tornem possível a produção dos produtos ou prestação de serviços, bem como outras tecnologias que permitam acessar os clientes onde quer que estejam. Por fim, um terceiro grupo de decisões que envolvem a criação de uma forma ordenada de trabalho com definições de funções, tarefas e processos que permitam que a empresa nascente seja bem sucedida em seus estágios iniciais e ao longo de seu crescimento.

Borges, Filion e Simard (2013) apontam a existência de quatro etapas no processo de criação de uma empresa: iniciação, preparação, lançamento e consolidação. Em cada uma dessas 
etapas, as decisões estão muitas vezes relacionadas à obtenção e aplicação de recursos de diversas naturezas. Os diferentes tipos de recursos que compõem a base para um novo empreendimento são humanos, sociais, financeiros, físicos, tecnológicos e organizacionais. Os recursos podem ser simples ou complexos. Recursos simples são tangíveis, descontínuos e baseados na propriedade; recursos complexos são intangíveis, sistemáticos e baseados no conhecimento. Pode-se também distinguir entre recursos utilitários e instrumentais. Os utilitários são aplicados diretamente no processo produtivo ou combinados para desenvolver outros recursos, enquanto que os instrumentais são usados para fornecer acesso a outros recursos (BRUSH, GREEN, HART, 2002).

De forma resumida, pode-se dizer que a criação de uma nova empresa envolve buscar e articular recursos diferentes que podem ser simples, tais como, matéria-prima ou dinheiro. Depois, é necessário pensar em capacidades e competências que envolvem a sistematização de procedimentos e são baseados em conhecimento, sendo, portanto, recursos complexos. Por fim, os recursos organizacionais mais complexos e de difícil imitação - ativos estratégicos e vantagem única - são fruto de esforço contínuo de inovação e diferenciação, permitindo à empresa se tornar mais competitiva em seu mercado (BRUSH, GREEN, HART, 2002). Argumento semelhante é sugerido por Flagestad e Hope (2001) no que diz respeito à criação de empresas em atividades turísticas e desenvolvimento de vantagens competitivas. De forma complementar, Lerner e Harber (2000) apontaram que o desempenho de empreendimentos no campo do turismo é afetado por aspectos de recursos internos e competências do empreendedor, além de aspectos ambientais e apoio institucional disponível na sociedade.

Embora, qualquer iniciativa empreendedora esteja vinculada a uma oportunidade para empreender, sendo a descoberta de oportunidades, a questão central da atividade do empreendedor (FILION, DOLABELA, 2000), a literatura de empreendedorismo tem apontado que um dos fatores de sucesso na criação de novas empresas é o capital social (BORGES, FILION, 2012; LIAO, WELSCH, 2005). A relevância do capital social para o entendimento do empreendedorismo também tem sido ressaltada em estudos no campo do turismo (MACBETH, CARSON, NORTHCOTE, 2004; ZHAO, RICHCIE, ECHTNER, 2011; PARK, LEE, CHOI, YOON, 2012). 
O capital social pode ser conceituado como a rede de relações do empreendedor e os recursos que podem ser mobilizados por meio dessa rede na construção e crescimento da empresa (BORGES, FILION, 2012). O capital social facilita aos potenciais empreendedores tanto a identificação quanto a aquisição de diferentes tipos de recursos. Para Anand, Glick e Manz (2002, p. 60), o capital social da organização refere-se ao conhecimento e à informação aos quais as organizações podem ter acesso, utilizando suas conexões formais e informais com agentes externos - como clientes, mão-de-obra terceirizada de outras organizações e assim por diante.

Estudos recentes têm investigado como as redes sociais são utilizadas por empreendedores tanto nas etapas iniciais da criação de uma empresa, quanto em seus estágios de crescimento (DUCCI, TEIXEIRA, 2011; CASSON, GIUSTA, 2007; BARROS, MOREIRA, 2006; DAVIDSSON; HONIG, 2003). O objetivo desse artigo é analisar o papel das redes sociais e do capital social no processo de constituição e crescimento da empresa KuritBike Cicloturismo Urbano, que atua em Curitiba/PR há cinco anos. Esta empresa surgiu a partir da percepção de uma oportunidade para empreender ofertando um serviço inovador inexistente em Curitiba.

Para atingir essa finalidade, o artigo conta com mais cinco seções além dessa introdução. Na próxima seção é apresentada uma revisão de trabalhos publicados na literatura que abordam os temas de redes sociais empreendedoras e capital social. Os dois temas são altamente relacionados e servem de base para análise do caso da empresa estudada. A terceira seção apresenta os procedimentos de pesquisa adotados na realização do estudo. Na quarta seção é feita uma apresentação da cidade de Curitiba para contextualizar o espaço geográfico de atuação da empresa. Nesta seção ainda se descrevem os aspectos centrais da empresa estudada. Na quinta seção, os resultados do estudo são apresentados. Por fim, a última seção conclui o trabalho apresentando os aspectos mais significativos do estudo realizado.

\section{Redes Sociais Empreendedoras e Capital Social}

Como afirmado na introdução, o capital social é um tema que tem atraído a atenção crescente na literatura das ciências sociais aplicadas (ANDERSON, MILLER, 2003: DE CAROLIS, SAPARITO, 2006; LIÑÁN, SANTOS, 2007). Inerente às discussões sobre capital social, encontra-se o debate sobre redes sociais formais ou informais. Afinal, é das redes de 
relacionamentos que empreendedores adquirem e desenvolvem seu capital social. O envolvimento em redes sociais é um componente central do capital social, pois é por meio delas que empreendedores obtêm acesso a informações, conhecimento e recursos que podem ser úteis na criação e crescimento de novos empreendimentos.

Esse crescente interesse pode ser justificado, principalmente, por razões de ordem econômica. A fonte de vantagem competitiva sustentável para empresas nascentes ou maduras reside muito mais nos conhecimentos e recursos externos no que em condições próprias das empresas, seja em termos de recursos ou informações internas. Principalmente no que diz respeito ao conhecimento, parece que junto ao desenvolvimento de conhecimento dos colaboradores, as empresas necessitam cada vez mais de competências relacionais que lhes permitam localizar e absorver conhecimentos exteriores com maior rapidez (CASSON, GIUSTA, 2007).

Desde os anos 80 do século passado, a literatura em empreendedorismo tem atribuído alta relevância ao estudo do impacto de redes e contatos sociais sobre o desempenho empreendedor. O estudo das redes sociais e do capital social pode ser relevante em um nível macro no sentido de subsidiar a formulação de políticas públicas de estímulo ao empreendedorismo (WOOLCOCK, 1998; WOOLCOCK; NARAYAN, 2000; PIAZZAGEORGI, 2002; CASSON, GIUSTA, 2007). Em um nível micro, há uma perspectiva emergente que sugere que empreendedores desenvolvem seu capital social construindo redes de contatos que fornecem fontes externas de informação, apoio, recursos financeiros e conhecimento, permitindo uma aprendizagem mais ampla (ANAND; GLICK; MANZ, 2002; GREVE. SALAFF, 2003; COPE, JACK, ROSE, 2007).

Segundo Abagli e Maciel (2002), a origem do termo Capital Social pode ser encontrada nos trabalhos de três pensadores das ciências sociais: Pierre Bourdieu, James Coleman e Robert Putnam. Abagli e Maciel (2002) comentam que Bourdieu usou essa expressão pela primeira vez no começo da década de 80 do século passado. Para Bourdieu, capital social envolve um conjunto de recursos reais ou potenciais, ligados ao envolvimento do indivíduo em uma rede estável de relações, que podem ser mais ou menos institucionalizadas, com mútua familiaridade e reconhecimento, provendo para cada um dos seus membros apoio oriundo do capital de propriedade coletiva (ABAGLI, MACIEL, 2002). 
A contribuição de James Coleman, conforme Abagli e Maciel (2002), foi centrada em um aprofundamento e refinamento do conceito de capital social, reforçando sua ligação causal com o acesso a recursos. Em 1990, Coleman definiu capital social como recursos sócio-estruturais que formam um ativo de capital individual, facilitando ações dos indivíduos que se encontram dentro dessa estrutura (ABAGLI, MACIEL, 2002).

Ainda na opinião de Abagli e Maciel (2002), outra contribuição significativa de Coleman foi a distinção que ele fez entre três formas de capital social. A primeira se relaciona com o nível de confiança e a extensão real das obrigações que existem em um ambiente social. O capital social é elevado quando há maior confiança entre as pessoas que aceitam obrigações mútuas. Outra forma de capital social origina-se de canais de trocas de ideias e informações. Por fim, a terceira manifestação do capital social se dá por meio de normas e sanções que estimulam as pessoas a se dedicarem a um bem comum, deixando de lado interesses egoísticos de curto ou longo prazo (ABAGLI, MACIEL, 2002).

Para Abagli e Maciel (2002), Robert Putnam é um dos autores mais citados no que diz respeito a capital social e é tido como o responsável pela popularização do termo, inclusive por sua incorporação no discurso político dominante. Em 1993, Putnam definiria capital social como aspectos da vida social, que envolvem redes, normas e confiança e levam à facilitação da ação e cooperação entre indivíduos que buscam objetivos comuns (ABAGLI, MACIEL, 2002). Esses autores e suas proposições têm, ao longo dos anos, inspirados trabalhos que investigaram a relação entre capital social e diversas dimensões do processo de criação de empresas.

Borges (2011), a partir de uma rigorosa discussão da noção de capital social individual, apresenta uma série de proposições que podem orientar a pesquisa sobre o papel do capital social do empreendedor na criação de empresas de base tecnológica. Neste sentido cabe destacar que o capital social pode ter diferentes contribuições em distintos momentos do processo empreendedor. Na fase de identificação de oportunidades, este proporciona acesso a informações e ideias com potencial de serem oportunidades de negócio, de forma que quanto maior a diversidade de contatos da rede, maior a possibilidade de acesso a informações e ideias com potencial de gerar oportunidades de negócio. De igual forma, quanto maior a diversidade de contatos da rede, maior é a possibilidade de acesso a informações e conhecimentos tecnológicos. No que diz respeito a acesso a recursos financeiros, quanto maior o número de 
contatos fortes, maior a possibilidade de acesso ao love money ${ }^{3}$. O capital social também ajuda a legitimar o empreendedor e sua empresa no mercado, sendo ainda, uma fonte de sócios e parceiros. A seguir apresentam-se estudos empíricos que investigaram a relação entre capital social e empreendedorismo.

Estudo comparativo entre empreendedores e não empreendedores realizado por Davidsson e Honig (2003) mostrou que o capital social baseado em laços fortes, tais como, pais e amigos que tiveram experiência empreendedora anterior e estímulo e apoio muito ativos por parte de pais e amigos é um forte preditor do envolvimento com atividades empreendedoras.

As aspirações de crescimento de empreendedores tecnológicos e não tecnológicos foram estudadas por Liao e Welsch (2003). Segundo estes autores, houve diferenças entre os dois grupos de empreendedores no que diz respeito à influência de cada dimensão do capital social. Para os empreendedores tecnológicos, o capital estrutural, i.e, a presença de muitos e diversos laços sociais não apresentou impacto quanto às aspirações de crescimento. No entanto, para os empreendedores não tecnológicos, laços sociais intensivos aumentam sua aspiração de crescimento. O capital relacional - confiança e confiabilidade - mostrou-se positivamente associado à aspiração de crescimento de ambos os grupos, mas com maior intensidade entre os empreendedores tecnológicos. Por fim, o capital cognitivo, demonstrado por normas e valores compartilhados, contribui para as aspirações de crescimento de ambos os tipos de empreendedores. Isto ocorre porque esse tipo de capital melhora o acesso a fontes externas de aprendizagem e a eficiência na assimilação do conhecimento.

Também em um estudo com empreendedores de empresas de base tecnológica, Anderson, Park e Jack (2007) sugerem que o capital social não é algo possuído pelos empreendedores, mas deve ser visto como um artefato relacional social que é produzido em interações sociais que resulta de um sistema de conexões variadas desenvolvidas pelo empreendedor.

A evolução do capital social, ao longo do processo de criação de uma empresa foi o objeto de investigação relatada por Borges e Filion (2012). Nesse estudo, o processo de criação de empresas foi decomposto nas etapas de iniciação, preparação, lançamento e consolidação. $\mathrm{O}$ capital social mobilizado na etapa de iniciação é essencialmente tecnológico, mas este vai se

\footnotetext{
3 O significado de love money relaciona-se aos recursos financeiros que são obtidos junto a membros da rede social mais próxima do empreendedor (família e amigos) em condições muito menos custosas que as encontradas no mercado financeiro tradicional.
} 
diversificando até a etapa de consolidação. Nesta última etapa, os resultados apontaram o crescimento da mobilização da rede de negócios. O uso do capital social em diferentes momentos da criação de uma empresa também foi objeto de análise por Greve e Salaff (2003).

A construção de vantagem competitiva pode ser associada a processos de aquisição e exploração de conhecimento. As redes sociais do empreendedor como indicado nos estudos indicados são fonte de conhecimento. A relação entre capital social, aquisição e exploração de conhecimento foi objeto de estudo conduzido por Yli-Renko, Autio e Sapienza (2001). O capital social, por meio das dimensões de interação social e redes, mostrou-se associado com maior aquisição de conhecimento. Esta, por sua vez, foi positivamente associada com exploração do conhecimento para vantagem competitiva por meio de desenvolvimento de novos produtos, diferenciação tecnológica e eficiência em custos de vendas.

O tema da diferença de classes sociais e sua relação com a exploração de oportunidades para empreender, mediada pelo capital social, foi objeto de pesquisa realizada por Anderson e Miller (2003). As evidências apontaram que indivíduos originários de classes mais abastadas, possuíam capital humano maior e seus empreendimentos apresentavam maior lucratividade e potencial de crescimento. O capital social desses empreendedores também se mostrou mais elevado com redes sociais que proviam apoio aos negócios de forma mais efetiva, permitindo o reconhecimento e aproveitamento de oportunidade mais eficazmente.

No campo do turismo, a relação entre capital social, criação e desenvolvimento de novas empresas tem atraído a atenção de pesquisadores, tanto no Brasil como em outros países. Por exemplo, Ducci e Teixeira (2010) realizaram um estudo onde descrevem como as redes sociais foram utilizadas por um empreendedor para construção do capital social nas fases de criação e desenvolvimento de uma empresa. A empresa analisada é especializada na organização de viagens de férias e negócios. As autoras partem da noção de que redes sociais empreendedoras surgem quando os empreendedores usam as redes sociais como base de apoio para suas atividades empresariais. A relação entre capital social e redes sociais é explicitada por Ducci e Teixeira (2010) quando apontam que o primeiro é gerado pelas redes pessoais e profissionais do empreendedor. Além disso, o capital social pode ajudar o empreendedor em seus esforços de criação de uma nova empresa. 
Barros e Moreira (2006) exploraram a formação de capital social em um contexto de arranjos produtivos locais. Diferentemente de empresas isoladas, as empresas localizadas em arranjos produtivos locais são mais inclinadas a desenvolveram redes sociais empreendedoras. Assim, este contexto de atuação empresarial tem seu estudo justificado. O estudo foi realizado em uma região turística do estado do Ceará, nordeste do Brasil, e focou no segmento do turismo, especificamente a região de Canoa Quebrada. O estudo do caso dessa região revelou que os vínculos interorganizacionais eram pouco consistentes, devido principalmente ao baixo nível de confiança recíproca dos empreendedores localizados no arranjo produtivo estudado.

Estudo desenvolvido na Coréia do Sul investigou os fatores que influenciam a formação de capital social em comunidades rurais envolvidas com atividades no campo do turismo (PARK, LEE, CHOI, YOON, 2012). A partir de uma survey foram obtidas informações com 380 respondentes. A análise dos dados permitiu a identificação de dois grupos separados em alto e baixo capital social. Os empreendedores de maior capital social estavam envolvidos em atividades devenda de produtos agrícilas, preparação de refeições, hospedagem e programas de turismo experiencial.

A criação de novos empreendimentos turísticos e sua relação com o capital social foi analisada por Zhao, Ritchie e Echtner (2011) em um estudo realizado na China, também, em um contexto rural. Baseados em dados coletados com 482 respondentes, os autores encontaram uma forte influência do capital social na habilidade de um indivíduo para empreender e para criar um empreendimento turístico.

O ecoturismo baseado em comunidades e sua relação com capital social foi investigado em estudo de caso desenvolvido por Jones (2005). Na sua análise, a autora apontou que o elevado nível de capital social foi fundamental para a criação de um empreendimento de ecoturismo em Gâmbia.

Outro estudo no contexto do turismo rural foi apresentado por McGehee, Lee, O’Bannon e Perdue (2010). De caráter exploratório e quantitativo, a pesquisa buscou evindenciar a relação do capital social com outras formas de capital. Os tipos de capital explorados foram: Cultural (estórias e tradições musicais, alimentícias e artesanais); Natural (recursos naturais, vida selvagem e paisagens); Político (poder local e grupos de pessoas que defendem interesses locais); Humano (pessoas com formação e educação em níveis superiores); Estrutura física 
(instalações públicas e privadas para atividades turísticas e infra-estrutura de acesso); e Financeiro (recursos financeiros e acesso a empréstimos e outras formas de investimento). Os resultados apontaram que há uma relação positiva entre o capital social dos empreendedores e as outras formas de capital.

Grämgsjö e Gummwsson (2006) analisaram o caso de um esforço de cooperação entre hotéis de uma mesma localidade para atrair turistas para um destino. $\mathrm{O}$ caso em análise foi uma rede de cooperação de pequenos hotéis na cidade de Östersund na Suécia. Integravam esta rede de cooperação 12 hotéis e duas pensões, dos quais sete hotéis eram vinculados a cadeias hoteleiras. Focando em formas de co-opetição, ou seja, como os integrantes da rede competiam e cooperavam ao mesmo tempo, os autores revelaram que a construção do capital social desses empreendedores foi fruto do estabelecimento de um código de conduta coletiva e de três princípios orientadores que eram observados por todos: demonstrar entusiasmo, dedicar tempo e contribuir com fundos. Essa forma de agir demandou dos empreendedores a prática constante de três tipos de equilíbrio: o coletivo versus o individual; a cooperação versus a competição; e o planejamento e a ação.

A forma como o turismo afeta a vida de populações pobres e como impactos positivos podem ser estimulados foi examinada por Ashley, Boyd e Goodwin (2000). Para esses autores, o turismo pode ter tanto impactos positivos quanto negativos no que diz respeito ao capital social de empreendedores em populações mais pobres. Por um lado, o turismo pode estimular o capital social por meio do acesso a fundos e informações que ampliem as redes sociais. Mas, de forma adversa, conflitos sobre as ações de estímulo ao turismo e a possível exclusão das populações pobres das áreas de turismo podem levar á diminuição do capital social.

Por fim, Karlson (2005) argumenta que o desenvolvimento de pequenas empresas relacionadas ao turismo é favorecido por meio do capital social que se articula por meio de um sentimento de pertencimento a uma comunidade e pela prática da solidariedade. Junto a este tipo de capital social se agrega o capital social cultural que se origina das tradições e manifestações culturais de cada local. Para o autor, isso ocorre porque cada local é a materialização de um modo de vida que se caracteriza por valores próprios. É este modo de vida que permitirá o florescimento de pequenos empreendimentos turísticos. 
Este conjunto de trabalhos sobre a relação entre empreendedorismo e capital social demonstra que existe uma relação positiva mutuamente reforçadora entre esses dois fenômenos, seja no caso do empreendedorismo em geral, ou, no que importa para este estudo, nas ações empreendedoras no campo do turismo.

Os estudos analisados reforçam a ligação entre capital social, redes sociais empreendedoras e acesso a recursos tangíveis e intangíveis no processo de criação e desenvolvimento de novos negócios. Além disso, demonstram que o capital social, por meio de suas três dimensões estrutural, cognitivo e relacional, pode ter efeitos diferenciados sobre empreendedores. Ademais, o que deve ser ressaltado é que, quando comparados com a população em geral, os empreendedores se diferenciam não pela quantidade de capital social, mas pela forma como usam o capital social para obtenção e aplicação de recursos informacionais, materiais e financeiros.

Após essa apresentação de exemplos de pesquisas sobre o papel do capital social no empreendedorismo, na próxima seção são descritos os procedimentos de pesquisa adotados nesse estudo.

\section{Procedimentos de Pesquisa}

Neste trabalho foi utilizado o método do estudo de caso. Essa forma de pesquisa tem sido uma estratégia preferida dos pesquisadores quando procuram responder às questões de como e por que certos fenômenos ocorrem ou, ainda, quando há pouco controle sobre os eventos e, também, quando o foco de interesse é sobre fenômenos atuais que só poderão ser analisados em contexto de vida real (GODOY, 1995).

A empresa objeto do estudo foi escolhida devido a duas razões. Em primeiro lugar, seu surgimento ocorreu devido à percepção de uma oportunidade de empreender de forma inovadora. Esta oportunidade, percebida há quatro anos, levou à criação de uma empresa de cicloturismo que até o momento de realização do estudo era a única atuando nesse setor na cidade de Curitiba. Assim, o caráter inovador da empresa sugeriu que o caso poderia ser útil na exploração da influência do capital social no empreendedorismo. Ademais, como a empresa está operando desde 2010, o caso poderia revelar, também, aspectos do uso das redes de 
contatos e do capital social do empreendedor no desenvolvimento da empresas após seus momentos iniciais de criação.

Em um estudo de caso, geralmente, o pesquisador faz um levantamento de dados em diferentes momentos, utilizando diversas fontes de informações e tem como técnicas fundamentais de pesquisa a observação e a entrevista. Para o estudo aqui relatado, algumas simplificações foram feitas. Devido a limitações de tempo do dirigente da empresa, foi feita apenas uma entrevista que durou 50 minutos. A entrevista seguiu roteiro estruturado com perguntas abertas sobre a criação e o crescimento da empresa. Além da entrevista, foi feita uma observação das instalações da empresa, equipamentos e materiais de divulgação impressos. Esta observação foi feita por meio de uma visita guiada pelo próprio dirigente com duração de 40 minutos. Por fim, o site da empresa foi usado também como fonte de dados. Essa simplificação não afeta a caracterização do estudo como um caso único, visto que o mesmo utilizou-se de múltiplas fontes de evidência. A descrição dos resultados foi apresentada para o respondente que não fez nenhuma observação quanto a impropriedades ou equívocos na análise realizada. A coleta dos dados por meio da entrevista e da observação direta ocorreu em agosto de 2014.

A entrevista foi gravada e depois transcrita integralmente. Informações provenientes da visita à empresa foram anotadas para uso na análise do caso. Os dados do site da empresa foram usados para descrição da empresa, seu histórico e serviços ofertados aos clientes.

A análise dos dados foi qualitativa, tendo por base principal as informações coletadas na entrevista. Para analisar os dados coletados, utilizaram-se as mesmas categorias analíticas propostas em Ducci e Teixeira (2010) e Ducci e Teixeira (2011): tipos de redes sociais e tipos de recursos acessados. Para isso, após várias leituras da transcrição da entrevista, foram identificados excertos da fala do respondente que pudessem ilustrar ou exemplificar as categorias analíticas adotadas.

Concluída a apresentação dos procedimentos de pesquisa adotados nesse trabalho, na próxima seção apresenta-se uma breve descrição da cidade de Curitiba, onde foi percebida a oportunidade de criação de uma empresa de cicloturismo por um jovem empreendedor. $\mathrm{Na}$ mesma seção faz-se, também, uma descrição da empresa estudada nessa pesquisa. 


\section{Contexto do Estudo: Curitiba e a empresa}

Curitiba, capital do Paraná, foi fundada em 29 de março de 1693. Atualmente, 322 anos depois, a cidade conta com mais de 1,8 milhões de habitantes. No site www.curitiba.pr.gov.br descobre-se que "Curitiba é uma palavra de origem Guarani: kur yt yba quer dizer "grande quantidade de pinheiros, pinheiral", na linguagem dos índios, primeiros habitantes do território". Esse nome se deve à existência de uma grande quantidade de Araucária angustifólia, o pinheiro-do-Paraná na região (http://www.curitiba.pr.gov.br/conteudo/perfil-dacidade-de-curitiba/174).

Na mesma fonte, aprende-se que Curitiba está distante cerca de 70 quilômetros do litoral do Paraná, a quase mil metros de altitude. A cidade dispõe de uma área verde muito ampla, contando com vários parques que foram implantados a partir de 1962, com exceção do Passeio Público na área central que existe desde 1886. Entre os parques que são muito visitados por turistas e que fazem parte dos roteiros da empresa, encontram-se o Barigui, o Jardim, Botânico,

o São Lourenço, o Tingui, $O$ Tanguá e o Bosque do Papa (http://www.curitiba.pr.gov.br/conteudo/perfil-da-cidade-de-curitiba/174)

Segundo informações do Instituto de Pesquisa e Planejamento Urbano de Curitiba - IPPUC, desde 1965 o planejamento urbano da cidade baseia-se no tripé Transporte Coletivo/Sistema Viário/Uso do Solo, cujo objetivo é a integração das estruturas física e funcional da cidade e direcionamento de seu crescimento de forma linearizada (IPPUC, 2004). O IPPUC também informa que Curitiba foi pioneira na implantação de redes de ciclovia sendo que atualmente a cidade conta com $81 \mathrm{~km}$ de ciclovias compartilhadas, $35 \mathrm{~km}$ de ciclovia exclusiva, e 9,4 km de ciclovia em construção ao longo da Linha Verde (IPPUC, 2008).

Esta preocupação com a garantia de meios alternativos de mobilidade urbana pode ser vista como a fonte de oportunidade percebida pelo empreendedor da empresa estudada nessa pesquisa. A disponibilidade de ciclovias permite que um maior número de pessoas possa utilizar a bicicleta como um meio de transporte, desde habitantes da cidade até turistas que venham passear em Curitiba.

No site da empresa Kuritbike, está registrado que seu surgimento, em 2010, teve o objetivo de atender a necessidade das pessoas que querem experimentar uma nova cidade de uma maneira 
mais intensa. Kuritbike é uma mistura da palavra indígena "Kurit" que significa pinheiro e da palavra do inglês "Bike" que sua tradução para o português é bicicleta (kuritbike.com.br).

A própria concepção do nome da empresa já indica uma forma inovadora de empreender. Segundo seu idealizador:

O uso da palavra indígena "Kurit" representa o elemento elo da trilogia formada pelos seguintes elementos: pinheiro que remete a natureza, o índio que remete ao homem e a bicicleta remetendo a tecnologia formando assim uma aliança em benefício ao meio ambiente como um todo.

O fundador da empresa, músico de formação, atualmente com 33 anos de idade, explicou sua motivação da seguinte forma:

Primeiro de tudo uma crise profissional com meu trabalho anterior. Quando vim para Curitiba a trabalho em 2007, deixei a bicicleta em Florianópolis onde eu morava, ... depois de 3 anos sem a bike, comecei a sentir falta e junto com a crise profissional quis fazer alguma coisa diferente, ai comprei a bicicleta para começar a pedalar na cidade... foi quando me dei conta que eu morava há 3 anos e não conhecia praticamente nada e ai com a bicicleta comecei a conhecer a cidade mais interessante, completamente diferente, e ai foi meu despertar: porque eu não monto um negócio onde eu possa mostrar para as pessoas esta cidade que eu estou conhecendo agora e não a que eu vivi durante estes 3 anos?

Concebendo a empresa por meio de um processo de planejamento formal, com a elaboração de uma plano de negócio, o empreendedor teve a preocupação em, desde os primeiros momentos da empresa, definir sua missão:

Contribuir para uma cidade mais humana através do fomento da ciclomobilidade de variadas formas ao proporcionar lazer e cultura em passeios ciclísticos agradáveis e seguros, apoiar pessoas e empresas interessadas em adotar a bicicleta como meio de transporte e disseminar informações sobre o impacto positivo do transporte não motorizado num contexto urbano. (www.kuritbike.com.br)

A empresa é pioneira no Brasil na oferta do Cicloturismo Urbano. Em Curitiba, foi a primeira a oferecer o serviço de aluguel de bicicletas diário. No cicloturismo, disponibiliza nove roteiros que passam por cerca de $150 \mathrm{~km}$ de rotas seguras e mapeadas.A empresa integra o Núcleo de Turismo Receptivo, um grupo de agências e pequenas operadoras do setor de turismo receptivo em Curitiba fundado em 2008. As atividades do Núcleo de Turismo Receptivo envolvem atendimento a turistas e empresas em parceria ou individuais em vários serviços, tais como, hotelaria, transporte, eventos, entre outros.A Kuritbike também integra o Convention Bureaux e tem parceria com a Serra Verde Express, empresa que atua no transporte de turistas de 
Curitiba para o Litoral do Paraná por meio da oferta de um serviço de trem turístico. Nessa parceira, a Kuritbike montou uma base de locação no saguão de embarque do trem turístico na Rodoferroviária em Curitiba.

Um aspecto relevante que foi observado durante a visita à empresa é que esta compartilha com o Hostel Internacional a localização em um mesmo terreno. Essa proximidade permitiu a realização de ações em conjunto, caracterizando uma rede social informal com benefícios mútuos. Para a empresa, hóspedes do Hostel tem acesso direto às instalações e podem ter descontos.

Pode-se observar também uma preocupação com a reutilização de recursos materiais e reaproveitamento de embalagens, adaptando-as para o uso como armários de estocagem das bicicletas e peças de reposição. Essas ações enfatizam o caráter criativo e inovador do empreendedor, associados com o movimento em favor da sustentabilidade, de forma consistente com sua missão.

É nesse contexto urbano, a partir de uma percepção diferenciada das possibilidades de abertura de um negócio inovador que surgiu a empresa. Nas próprias palavras do empreendedor:

O que eu pensei foi o seguinte: a gente procura sempre trazer o presente da cidade, ou resgatar coisas que existem há muito tempo e, às vezes, não tenha sido explorado ainda. Exemplo disso é o nosso serviço, a gente tem uma grande gama de atrativos ligados à natureza na cidade, nossos parques, uma malha cicloviária em torno de 120 quilômetros que conecta a maioria dessas áreas de interesses turísticos e, até então, desde a década de 80, não existia nenhuma empresa que fazia esse tipo de serviço.

$\mathrm{Na}$ próxima seção, se analisa o papel das redes sociais e do capital social na criação e desenvolvimento dessa empresa.

\section{Análise do Caso}

A análise dos dados coletados foi estruturada em duas partes: a fase de criação da empresa; e a fase de seu crescimento. Em cada uma das fases, procurou-se identificar o uso de redes sociais formais e informais e o tipo de recursos que essas redes propiciaram ao empreendedor. 


\subsection{A fase de criação da empresa}

Nessa fase inicial, o entrevistado comentou que tinha contatos com amigos que eram proprietários de uma empresa de cicloturismo convencional em Florianópolis. Como não tinha nada parecido com o que queria fazer no Brasil, foi procurar experiências fora do país, por meio de sites, encontrando uma empresa em Buenos Aires, algumas na Europa e nos Estados Unidos.

Nesse primeiro momento, apesar de ter uma potencial rede informal, os amigos, o empreendedor buscou recursos informacionais ao invés de usar a rede de amigos. Como ele mesmo disse:

As que mais eu me identifiquei foram essas duas (o entrevistado se refere às empresas de Buenos Aires e Paris) onde peguei mais referências, até pela linguagem do site, acesso as informações aquela coisa toda, então essas duas foram as referências e comecei a fazer alguma coisa assim que é como eu imaginava.

Outro tipo de recurso utilizado nessa fase foi o financeiro, que ele obteve através de alguns amigos, com investimento do tipo $\mathrm{Anjo}^{4}$. Esse evento demonstra também que esse tipo de recurso surgiu pela utilização de uma rede social informal composta pelos amigos. Ao mesmo tempo, o respondente informou dificuldades de acessar as fontes formais de financiamento, o que reforçou o papel facilitador da rede informal com o investimento anjo. Em suas palavras:

Quando eu cheguei nas instituições, sejam públicas ou privadas, barrou num caráter que para eles é crucial na hora de emprestar dinheiro ou não, é o risco. Uma empresa que ainda não existe é risco absurdo, não tem... Eu precisava das bicicletas para operar, como eu ia fazer? Como eu ia começar meu negócio? Foi quando, numa mesa de boteco, o investidor Anjo, entre amigos, disse: eu vou te emprestar o dinheiro para você abrir esse negócio, ele emprestou, depois paguei pra ele.

Ainda na fase de criação, o respondente declarou que elaborou um plano de negócio antes de abrir a empresa. Nessa atividade contou com apoio do Serviço Brasileiro de Apoio às Micro e Pequenas Empresas do Paraná (SEBRAE-PR) que tinha um programa de orientação chamado

\footnotetext{
4 O Investimento-Anjo é o investimento efetuado por pessoas físicas com seu capital próprio em empresas nascentes com alto potencial de crescimento (as startups) apresentando as seguintes características: 1 . É efetuado por profissionais (empresários, executivos e profissionais liberais) experientes, que agregam valor para o empreendedor com seus conhecimentos, experiência e rede de relacionamentos além dos recursos financeiros, por isto é conhecido como smart-money. 2. Tem normalmente uma participação minoritária no negócio. 3. Não tem posição executiva na empresa, mas apóiam o empreendedor atuando como um mentor/conselheiro (http://www.anjosdobrasil.net/o-que-eacute-um-investidor-anjo.html)
} 
Agência Fácil. Este evento mostra o acesso de recursos informacionais por meio de uma rede formal. Esses recursos tiveram a forma de material disponibilizado em site.

Um aspecto relevante que surgiu na entrevista, diz respeito ao histórico de vida do empreendedor, um tipo de capital humano do empreendedor, como visto na revisão da literatura. $\mathrm{O}$ empreendedor sempre esteve envolvido com o uso da bicicleta como um meio de locomoção, muito antes do tema se tornar tão na moda como ele disse. Esse histórico de vida, que lhe permitiu conhecer sobre aspectos funcionais do negócio, foi fundamental na criação da empresa, conforme relatou o entrevistado:

O que é legal é o seguinte, eu tinha todo um perfil e histórico, por exemplo, afinidade com bicicleta, que não é uma coisa assim tipo ah bicicleta é um negócio que tá na moda, eu não tive que adquirir conhecimento sobre isso, eu já tinha feito viagem pelo Brasil então tinha muita vivência com bike, sempre fui um ciclotur, usuário da bicicleta como meio de transporte na cidade, conhecia a lógica de funcionamento, como se portar, capital de conhecimento eu já tinha, principalmente as coisas das línguas é fundamental pra esse trabalho.

Em síntese, na fase de criação da empresa foram usadas redes informais e formais que deram acesso a recursos informacionais e financeiros, bem como a motivação e o conhecimento sobre cicloturismo do empreendedor. Para o respondente essa não foi uma fase crítica, mas o crescimento e desenvolvimento da empresa é que apresentaram desafios.

\subsection{Fase de crescimento da empresa}

A fase de crescimento, na opinião do entrevistado, tem sido mais crítica do que os momentos iniciais. Segundo ele, isso ocorre porque a empresa começou a ser conhecida no mercado e passou a ter dificuldades de atender à demanda crescente. Para ele,

O momento mais crítico, vou te falar uma coisa, não foi nem no começo, o mais crítico sabe quando foi, quando a empresa começou a tomar repercussão, este foi o momento mais crítico, começou a se consolidar, ter presença forte na internet, através de nosso site, parceiros, recomendações, enfim, a gente começou a ter uma inserção no trade de turismo e reconhecimento entre outras empresas. Não conseguia mais dar conta dessa demanda entendeu?A demanda cresceu e a gente não conseguia atender, atender com qualidade, não tinha bike suficiente... então o momento mais crítico foi justamente o de crescimento da demanda que não foi acompanhada com o crescimento de investimento.

De certa forma, ao relatar esses momentos críticos de crescimento, o empreendedor já revela em seu discurso o uso de redes informais e formais para alavancar a expansão da empresa. Do 
ponto de vista de capital social relacional surge a inserção no trade de turismo $e$ reconhecimento entre outras empresas, levando ao surgimento de um recurso intangível que é a reputação da empresa.

Ao mesmo tempo, para dar conta da falta de recurso, o empreendedor vai se apoiar em parceiros, mas principalmente na entrada de um sócio que ajudou a enfrentar essas dificuldades no crescimento inicial de atividades. Além disso, o entrevistado informou a realização de algumas parcerias, o que indica a utilização de redes sociais para obtenção de recursos. Entre essas houve uma parceria com a bicicletaria Puma que fornecia bicicletas adicionais quando necessário. Outra parceria foi com o Hostel Internacional que ajudou na divulgação dos serviços. O empreendedor se filiou ao Núcleo de Turismo Receptivo que passou a oferecer os serviços da KuritBike.

Nesse esforço o que se pode observar é a utilização de redes informais e formais. A parceria com a empresa PUMA foi de caráter informal e permitiu o acesso a recursos materiais. Por outro lado, a parceria com o Hostel Internacional, também informal, deu acesso a recursos informacionais, no sentido de divulgação dos serviços da empresa. No caso do Núcleo de Turismo Receptivo é uma utilização de rede social formal para obtenção de recursos de natureza informacional também.

No crescimento da empresa, uma nova oportunidade surgiu através de contatos com amigos que tinham uma empresa que estava prestando serviços de locação de bicicletas nos espaços públicos criados pela Prefeitura Municipal. Como a empresa desses amigos estava passando por dificuldades, ele foi convidado a operar três bicicletários, o que permitiu à empresa uma nova fonte de recursos financeiros pela prestação desse serviço. O que se vê nessa situação é, mais uma vez, o capital social oriundo de uma rede informal sendo utilizado como meio de crescimento da empresa.

Entre os fornecedores, o respondente informou o desenvolvimento de uma relação social que caracteriza o uso de uma rede formal que propicia o acesso a recursos materiais de forma mais facilitada. Como foi dito pelo empreendedor:

... o outro tipo de fornecedor é o que presta manutenção para a gente, esse aí é um grande parceiro e um dos padrinhos da empresa, a Kuritbike foi criada dentro dessa oficina de bicicleta, que aliás é muito comum no exterior também oficinas de bicicletas oferecerem biketur, ... no sentido de 
manutenção, a gente negocia, tem muita flexibilidade de pagamento e coloca prioridades e tal.

A empresa tem conseguido recursos financeiros por meio de vendas através de algumas parcerias informais, principalmente por meios das redes sociais na Internet. $\mathrm{O}$ entrevistado relatou que:

Hoje em dia já tem sites que são referência em divulgação de roteiros no mundo inteiro onde a gente está em destaque, Tripadvisor, tem os blogueiros, e aí a coisa vai tomando corpo, outras empresas de turismo passaram a vender nosso produto, então a gente já tem uma captação passiva através da internet e também ativa de distribuidores na cadeia de turismo.

Na mesma linha, o respondente informou que há empresas que estão percebendo os serviços oferecidos por ele, como um meio de comunicação com seus consumidores e desenvolvimento de uma imagem de responsabilidade social. Estas ações em conjunto possuem um caráter de rede social, ampliando o capital social do empreendedor, ao lhe permitir acesso a novos clientes, com recursos de outras empresas.

No que diz respeito à interação com órgãos de governo, o respondente informou que até o momento não havia tido nenhum, mas que planejava iniciar uma aproximação, visto que sua atuação empresarial está muito ligada aos espaços públicos de lazer e turismo.

Finalmente, quando perguntado sobre se costumava trocar ideias com outras pessoas sobre a gestão da empresa, o respondente revelou a importância de uma rede social formal já mencionada anteriormente, o Núcleo de Turismo Receptivo. Segundo ele:

Sim. Principalmente, e aqui que é legal porque nessa questão o papel crucial é do Núcleo de Turismo Receptivo, porque a proposta dele é inicialmente essa, botar as empresas de turismo receptivo em conjunto para que juntas amadureçam e entendam seu processo de operação e gestão. Então as pessoas que eu principalmente troco ideias, converso, peço referências, ajuda são através do Núcleo, até por que eles têm mais experiência no segmento.

Em síntese, na fase de crescimento da empresa, percebe-se o uso mais intenso de redes sociais informais e formais, dando acesso a diferentes tipos de recursos: informacionais, materiais, financeiros e sociais.

Dessa forma, tanto na fase de criação quanto na de crescimento da Kuritbike, o empreendedor fez uso de redes formais e informais para obter acesso a diferentes tipos de recursos. O que se pode notar é que, de uma fase para a outra, houve uma ampliação dos tipos de recursos obtidos nas redes sociais. Na primeira houve predomínio de recursos informacionais e financeiros, e na 
segunda, além desses foram obtidos recursos materiais e simbólicos, especialmente na forma de consolidação da reputação da empresa.

\section{Conclusão}

Este estudo permitiu ilustrar, por meio de um estudo de caso, que as redes sociais são uma importante fonte de capital social para o empreendedor, tanto na fase de criação quanto na fase de crescimento da empresa. Como pode ser percebido por meio das falas do entrevistado, em muitos momentos houve acesso a recursos financeiros, informacionais e sociais que surgiram por meio de redes formais e informais.

Esse resultado se assemelha aos obtidos nos estudos de Ducci e Teixeira (2010; 2011). No entanto, houve uma diferença que deve ser destacada. Ducci e Teixeira (2010) relataram que o empreendedor encontrou maiores dificuldades na fase de criação da empresa, o que não ocorreu no caso aqui analisado. No caso da KuritBike, a fase de criação da empresa não apresentou muitas dificuldades. Estas têm sido mais frequentes na fase de crescimento.

Essa diferença pode ser atribuída ao caráter inovador da empresa e sua presença única no mercado. Por um lado, uma inovação no mercado, em geral, demanda um período de tempo mais longo para ser aceito de forma mais ampla pelos consumidores. Por outro lado, por ser a única empresa atuando no setor, isto torna o serviço oferecido pela empresa menos visível no mercado, o que pode levar a dificuldades de manutenção da mesma no mercado. Caso houvesse mais empresas atuando no setor, este tipo de serviço seria objeto de maiores esforços de divulgação, podendo beneficiar de forma coletiva a todas as empresas que eventualmente atuassem neste tipo de serviço.

De qualquer forma, observa-se que o empreendedor tem buscado apoio em suas diferentes redes de contatos para consolidar a empresa no mercado. Pois, assim como foi apontado na literatura abordada anteriormente, é da interação entre motivação, capital humano do empreendedor e utilização das redes sociais para aquisição de recursos que se pode explicar a permanência da empresa por quatro anos nesse contexto, com perspectivas favoráveis de continuar no mercado. 
O principal aprendizado que se extrai do caso analisado é que o processo de criação de empresas, conforme aqui evidenciado, exige do empreendedor uma grande capacidade de articulação de recursos de diferentes naturezas. Essa articulação se torna menos complexa quando o empreendedor utiliza um maior nível de capital social oriundo de sua convivência em diferentes redes sociais, sejam elas constituídas formal ou informalmente. São as redes sociais que tornam menos difícil o acesso a recursos que ampliam as possibilidades de sucesso na criação e desenvolvimento de uma empresa.

Em síntese, pode-se dizer que o caso aqui analisado reforça a ideia proposta por Anderson, Park e Jack (2007) de que o capital social é um artefato relacional social que permite ao empreendedor acesso a um complexo conjunto de recursos tangíveis e intangíveis que são utilizados na criação e crescimento de sua empresa.

\section{Referências}

ABAGLI, S.; MACIEL, M. L. Capital social e empreendedorismo local. Rio de Janeiro; Rede Pesquisa em Sistemas Produtivos e Inovativos Locais, 2002, 28p.

ANAND, V.; GLICK, W. H.; MANZ, C.C. Capital social: explorando a rede de relações da empresa. Revista de Administração de Empresas, vol. 42, n. 4, p. 57-71, 2002.

ANDERSON, A. R.; MILLER, C. J. Class matters: human and social capital in the entrepreneurial process. Journal of Socio-Economics, vol. 32, p. 17-36, 2003.

ANDERSON, A.; PARK, J.; JACK, S. Entrepreneurial social capital: conceptualizing social capital in new high-tech firms. International Small Business Journal, vol. 25, n. 3, p. 245-272, 2007.

ASHLEY, C.; BOYD, C. GOODWIN, H. Pro-poor tourism: putting poverty at the heart of the tourism agenda. Natural Resources Perspective, n. 51, p. 1-6, 2000.

BARROS, F.S. DE O.; MOREIRA, M. V. C. O capital social nas aglomerações produtivas de micro e pequenas empresas: estudo de um arranjo produtivo turístico. Organizações \& Sociedade, vol. 13, n. 39, p. 113-130, 2006.

BORGES, C. O papel do capital social do empreendedor na criação de empresas tecnológica. Revista de Administração e Inovação, vol.8, n. 2, p.162-181, 2011.

BORGES, C.; FILION, L. Evolução do capital social empreendedor dos spin-offs universitários. Revista de Empreendedorismo e Gestão de Pequenas Empresas, vol.1, n. 1, p. 1-31, 2012.

BORGES, C.; FILION, L. J; SIMARD, G. Criação de Empresas: um processo mais rápido e fácil resulta em empresas de melhor desempenho? Revista de Ciências da Administração, vol. 15, n. 35, p. 196-207, 2013.

BRUSH, Cândida G.; GREENE, Patrícia G.; HART, Myra M. Empreendedorismo e construção da base de recursos. Revista de Administração de Empresas, vol. 42, n. 1, jan/mar, p. 20-35, 2002. 
CASSON, M.; GIUSTA, M. D. Entrepreneurship and Social Capital: Analysing the Impact of Social Networks on Entrepreneurial Activity from a Rational Action Perspective. International Small Business Journal, vol. 25, n.3, p. 220-244, 2007.

COPE, J.; JACK, S.; ROSE, M.B. Social Capital and Entrepreneruship: an introduction. International Small Business Journal, vol. 25, n. 3, p. 213-219, 2007.

DAVIDSSON, P.; HONIG, B. The Role of Social and Human Capital among Nascent Entrepreneurs. Journal of Business Venturing, vol. 18, p. 301-331, 2003.

DE CAROLIS, D. M.; SAPARITO, P. Social Capital, Cognition, and Entrepreneurial Opportunities: A Theoretical Framework. Entrepreneurship Theory and Practice, vol. 30, n. 1, p. 41-56, 2006.

DUCCI, N. P. C.; TEIXEIRA. R. M. Articulação de redes sociais por empreendedores na formação do capital social. Turismo: Visão e Ação, vol. 21, n. 1, p. 165-189. 2010.

DUCCI, N. P. C.; TEIXEIRA. R. M. As redes sociais dos empreendedoras na formação do capital social: um estudo de casos múltiplos em municípios do norte pioneiro do estado do Paraná. Caderno EBAPE.Br, vol.9, n.4, p. 967-997, 2011.

FILION, Louis Jacques; DOLABELA, Fernando Boa idéia! E agora? São Paulo: Cultura, 2000.

FLAGESTAD, A.; HOPE, C. A. Strategic success in winter sports destinations: a sustainable value creation perspective. Tourism Management, vol. 22, n. 5, p. 445-461, 2001.

GODOY, A. S. Pesquisa Qualitativa Tipos Fundamentais. Revista de Administração de Empresas. vol. 35, n. 3, p. 20-29, 1995.

GRÄNGSJÖ, Y von F.; GUMMESSON, E. Hotel networks and social capital in destination marketing. International Journal of Service Industry Management, vol. 17, n. 1, p. 58-75, 2006.

GREVE, A.; SALAFF, J. W. Social Networks and Entrepreneurship. Entrepreneurship Theory and Practice, vol.28, n. 1, p. 1-22, 2003.

IPPUC - Instituto de Pesquisa e Planejamento Urbano. Planos Setoriais. Relatórios 2008. Curitiba: IPPUC, 2008.

IPPUC - Instituto de Pesquisa e Planejamento Urbano. Plano Diretor 2004. O planejamento urbano de Curitiba. Curitiba: IPPUC, 2004.

JONES, S. Community-based Ecotourism: the significance of social capital. Annals of Tourism Research, vol. 32, n, 2, p. 303-324, 2005.

KARLSON, S-E. The Social and the Cultural Capital of a Place and their Influence on the Production of Tourism - A Theoretical Reflection based on an Illustrative Case Study. Scandinavian Journal of Hospitality and Tourism, vol. 5, n. 2, p. 102-115, 2005.

LERNER, M.; HARBER, S. Performance factors of small tourism ventures: the interface of tourism, entrepreneurship and the environment. Journal of Business Venturing, vol. 16, n. 1, p. 77-100, 2000.

LIAO, J.; WELSCH, H. Roles of Social Capital in Venture Creation: Key Dimensions and Research Implications. Journal of Small Business Management, vol. 43, n. 4, p. 345-362, 2005.

LIAO, J.; WELSCH, H. Social Capital and Entrepreneurial Growth Aspiration: a Comparison of Technology- and non-Technology-based nascent entrepreneurs. Journal of High Tecchnologu Management Research, vol. 14, p. 149-170, 2003.

LIÑÁN, F.; SANTOS, F.J. Does Social Capital Affect Entrepreneurial Intentions? International Advances in Economic Research, vol. 13, p. 443-453, 2007. 
MACBETH, J.; CARSON, D.; NORTHCOTE, J. Social Capital, Tourism and Regional Development: SPCC as a Basis for Innovation and Sustainability. Current Issues in Tourism, vol. 7, n. 6, p. 502-522, 2006.

McGEHEE, N. L.; LEE, S.; O’BANNON, T. L.; PERDUE, R. R. Tourism-related Social Capital and Its Relationship with Other Forms of Capital: An Exploratory Study. Journal of Travel Research, vol. 49, n. 4, p. 486-500, 2010.

PARK, D-B; LEE, K-C; CHOI, H-J; YOON, Y. Factors influencing social capital in rural tourism communities in South Korea. Tourism Management, v. 33, n. 6, p. 1511-1520, 2012.

PIAZZA-GEORGI, B. The role of human and social capital in growth: extending our understanding. Cambridge Journal of Economics, vol. 26, p. 461-479, 2002.

YLI-RENKO, H.; AUTIO, E.; SAPIENZA, H.J. Social Capital, Knowledge Acquisition, and Knowledge Exploitation in Young Technology-Based Firms. Strategic Management Journal, vol. 22, p. 587-613, 2001.

WOOLCOCK, M. Social capital and economic development: toward a theoretical synthesis and policy framework. Theory and Society, vol. 25, p. 151-208, 1998.

WOOLCOCK, M; NARAYAN, D. Social capital: implications for development theory, research and policy. The World Bank Research Observer, vol. 15, n. 2, p. 225-249, 2000.

ZHAO, W.; RITCHIE, J. R.; ECHTNER, C. M. Social capital and tourism entrepreneurship. Annals of Tourism Research, v. 38, n. 4, p. 1570-1595, 2011.

Sites Consultados:

www.anjosdobrasil.net

www.curitiba.pr.gov.br

www.kuritbike.com.br

Recebido em: $22 / 09 / 2014$ ( $1^{\text {a }}$ versão $)$ 08/10/2015 ( $2^{\mathrm{a}}$ versão)

Aprovado em: 14/10/2015 